\title{
Oncologist betion
}

\section{A Phase II Study of Pazopanib in Patients with Recurrent or Metastatic Invasive Breast Carcinoma: A Trial of the Princess Margaret Hospital Phase II Consortium}

\author{
Sara K. Taylor,,${ }^{a, b, c}$ STephen Chia, ${ }^{\text {a,d }}$ Susan Dent, ${ }^{\text {a,e }}$ Mark Clemons,,${ }^{\text {a,b,e }}$ Mark Agulnik,, a,b,f \\ Pamela Grenci, ${ }^{\text {a,b }}$ Lisa Wang,,${ }^{\text {a,b }}$ Amit M. Oza,,${ }^{\text {a,b }}$ Percy Ivy,${ }^{\mathrm{g}}$ Kathleen I. Pritchard,,${ }^{\text {a,c,h }}$ \\ NATASHA B. LEIGHL ${ }^{\text {a,b }}$
}

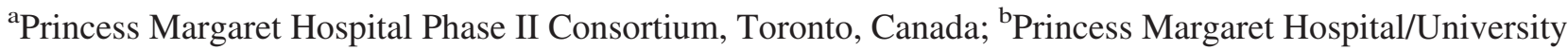
Health Network, Toronto, Canada; ${ }^{\mathrm{c} S u n n y b r o o k}$ Odette Cancer Centre, Toronto, Canada; ${ }^{\mathrm{d} B r i t i s h}$ Columbia Cancer Agency, Vancouver, Canada; ${ }^{\mathrm{e}}$ The Ottawa Hospital Cancer Centre, Ottawa, Canada; ${ }^{\mathrm{f}}$ Northwestern University, Feinberg School of Medicine, Chicago, Illinois, USA; ${ }^{\mathrm{g}}$ National Cancer Institute Cancer Therapy

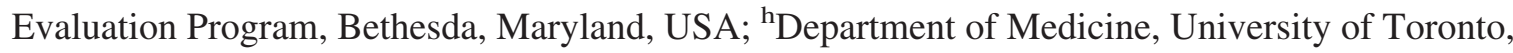
Toronto, Canada

Key Words. Breast neoplasms • Pazopanib • Targeted therapy • Phase II

\begin{abstract}
Disclosures: Sara K. Taylor: None; Stephen Chia: Consultant/advisory role: GlaxoSmithKline; Susan Dent: Honoraria: GlaxoSmithKline; Mark Clemons: Consultant/advisory role: GlaxoSmithKline; Mark Agulnik: None; Pamela Grenci: None; Lisa Wang: None; Amit M. Oza: None; Percy Ivy: None; Kathleen I. Pritchard: Consultant/advisory role: ASCO Board of Directors; Expert testimony: AstraZeneca, Novartis. Natasha B. Leighl: None. This article discusses the investigational use of pazopanib in breast cancer.

The content of this article has been reviewed by independent peer reviewers to ensure that it is balanced, objective, and free from commercial bias. No financial relationships relevant to the content of this article have been disclosed by the independent peer reviewers.
\end{abstract}

\begin{abstract}
Purpose. Angiogenesis is an important hallmark of breast cancer growth and progression. Pazopanib, an oral small molecule inhibitor of vascular endothelial growth factor receptor, platelet-derived growth factor receptor, and KIT, has activity across a range of solid tumors. We evaluated the activity of singleagent pazopanib in recurrent or metastatic breast cancer (MBC).

Patients and Methods. Patients with recurrent breast cancer or MBC, treated with up to two prior lines of chemotherapy, were eligible to receive pazopanib, 800 mg daily until progression. The primary endpoint was

the objective response rate as measured by Response Evaluation Criteria in Solid Tumors. Secondary endpoints included time to progression, the stable disease rate, and toxicity. Using a two-stage design, confirmed response in three of 18 patients was required to proceed to stage 2.

Results. Twenty evaluable patients were treated, with a median age of 56 years; $70 \%$ were estrogen receptor positive, all were human epidermal growth factor receptor 2 negative. The majority had one or two prior lines of chemotherapy. One patient $(5 \%)$ had a partial response, $11(55 \%)$ had stable disease

Correspondence: Natasha B. Leighl, M.D., F.R.C.P.C., 5-105 610 University Avenue, Toronto, Ontario M5G 2M9, Canada. Telephone: 416-946-4645; Fax: 416-946-6545; e-mail: Natasha.Leighl@uhn.on.ca Received March 19, 2010; accepted for publication May 27, 2010; first published online in The Oncologist Express on August 3, 2010. CAlphaMed Press 1083-7159/2010/\$30.00/0 doi: 10.1634/ theoncologist.2010-0081
\end{abstract}


(SD) [four (20\%) with SD $\geq 6$ months], and seven $(35 \%)$ had progressive disease as their best response. One (5\%) was not evaluable. The median time to progression was 5.3 months. Pazopanib did not cause significant severe toxicity aside from grade 3-4 transaminitis, hypertension, and neutropenia in three patients each (14\% each) and grade 3 gastrointestinal hemorrhage in one patient $(5 \%)$.

Conclusion. Pazopanib provides disease stability in advanced breast cancer. The activity seen is comparable with that of other antiangiogenic agents in this setting. Pazopanib may be of interest for future studies in breast cancer, including in combination with other systemic agents. The Oncologist 2010;15:810-818

\section{INTRODUCTION}

Breast cancer is a leading cause of cancer mortality in women [1]. Metastatic breast cancer is considered incurable, with a median survival time of 20-24 months [2, 3]. Despite advances in systemic therapy, there has been only a modest improvement in survival in the past few decades, thus better agents are needed [3].

Angiogenesis is a key process in the growth and survival of breast cancer cells. A number of key proangiogenic factors, including vascular endothelial growth factor (VEGF) and its receptors (VEGFRs) $[4,5]$ and the class III receptor tyrosine kinases platelet-derived growth factor receptor (PDGFR) $[6,7]$ and stem cell factor receptor (KIT), are overexpressed in breast cancer [8-10]. Many of these are associated with a poor prognosis [11-14] and a poor response to systemic chemotherapy in advanced breast cancer patients [13-15].

VEGF inhibitors have shown efficacy in cancer, including breast cancer [16]. Combined targeting of both VEGFR and PDGFR- $\beta$ has shown promise in preclinical models [17]. The growth factors VEGF and PDGF are also known to promote lymphangiogenesis, thereby leading to nodal metastasis [18]. Therefore, a combined approach directed at multiple targets with a multikinase inhibitor to suppress angiogenesis and lymphogenesis is an attractive proposition [19].

Pazopanib (Votrient ${ }^{\mathrm{TM}}$; GlaxoSmithKline, Philadelphia) is an oral small molecule tyrosine kinase inhibitor of VEGFR-1, VEGFR-2, VEGFR-3, PDGFR- $\alpha$, PDGFR- $\beta$, and KIT [20]. A phase I study of pazopanib in 63 patients with relapsed or refractory solid tumors, including five with breast cancer, reached doses up to 2,000 mg daily. The maximum-tolerated dose was not reached [21]. Because the steady-state exposure to pazopanib was saturated at doses of $800-2,000 \mathrm{mg}$ daily, the $2,000 \mathrm{mg}$ /day cohort was not fully evaluated. Antitumor activity was seen with daily doses $\geq 800 \mathrm{mg}$, and this was well tolerated. No further increase in plasma concentration of pazopanib was seen with higher doses; therefore, the 800-mg dose was selected as the recommended phase II dose for future trials. Pazopanib has been approved by the U.S. Food and Drug Administration for the treatment of advanced renal cell carcinoma [22].

Here, we report the results of a multicenter, open-label, single-arm, phase II trial to evaluate the safety and efficacy of pazopanib in human epidermal growth factor receptor (HER)-2 nonoverexpressing recurrent breast cancer or metastatic breast cancer (MBC) patients.

\section{Materials AND Methods}

\section{Patients}

The study population consisted of patients aged $\geq 18$ years with histologically or cytologically confirmed incurable recurrent breast cancer or invasive MBC. Patients were permitted up to two lines of prior chemotherapy (including neoadjuvant or adjuvant), had no limit on lines of endocrine therapy, and were required to have adequate hematologic, renal, and hepatic function, adequately controlled blood pressure ( $\leq 140 / 90 \mathrm{mmHg}$ ), an Eastern Cooperative Oncology Group performance status score of 0 or 1 , and measurable disease by the Response Evaluation Criteria in Solid Tumors (RECIST) [23]. Patients were excluded for serious comorbidities, known brain metastasis, and prior bevacizumab or other angiogenesis inhibitor therapy.

\section{Study Design}

In this single-arm, open-label, phase II study, patients were recruited from three Canadian cancer centers in the Princess Margaret Hospital Phase II Consortium. The primary endpoint was antitumor efficacy measured by the objective response rate (ORR) per the RECIST. Secondary endpoints included the duration of response, rate and duration of stable disease (SD), 6-month progression-free survival (PFS) rate, time to progression (TTP), overall survival, and safety and tolerability of pazopanib. Duration of response was measured from the date of first response to the date of progression as measured by the RECIST. SD duration was measured from the start of treatment until progression. PFS was measured from the date of study enrollment to disease progression, death, or last contact, or last tumor assessment before the start of further antitumor therapy. Prolonged SD 
(pSD), defined as SD lasting $\geq 6$ months, and the clinical benefit rate (CBR), defined as the rate of complete response, partial response (PR), and $\mathrm{pSD}$, were determined but were not prospectively defined in the protocol.

This study was approved by the local institutional ethics boards. All patients provided written informed consent.

\section{Treatment}

Patients self-administered pazopanib, $800 \mathrm{mg}$ orally, daily continuously in 28-day cycles, and kept a medication diary, which was reviewed by a study nurse to confirm compliance. Treatment was continued until disease progression, unacceptable toxicity, or patient request to discontinue. Dose reductions (200-mg increments to a minimum of 400 $\mathrm{mg} /$ day) or delays were instituted according to the occurrence of treatment-related adverse events as specified in the protocol. The pazopanib dose was reduced (or held for up to 14 days) for grade $\geq 3$ nonhematologic or grade $\geq 4$ hematologic adverse events related to pazopanib and lasting $>5$ days that persisted at grade $\geq 3$ despite maximum supportive care for $\leq 48$ hours. Patients were removed from the study if the adverse event did not resolve to grade $\leq 2$ after treating at the lowest (e.g., $400 \mathrm{mg}$ ) dose reduction. Specific additional measures included dose reductions for persistent grade 2 hypertension and treatment delays for grade 2 hemorrhage until resolution to grade $\leq 1$, and then treatment was reinstituted at a reduced dose. Treatment was discontinued for grade $\geq 3$ hemorrhage.

\section{Assessments}

Baseline investigations were performed within 4 weeks of starting study treatment and included a history, physical examination, laboratory tests $(\mathrm{CBC}$, international normalized ratio, partial thromboplastin time, serum chemistry, serum creatinine, urinary protein assessment), electrocardiogram, and radiologic imaging of the tumor via computed tomography or magnetic resonance imaging. Patients had a physical examination and blood tests every 4 weeks and tumor imaging every 8 weeks until tumor progression. Patients kept a diary of self-monitored blood pressure readings twice daily, and blood pressure was recorded every other week by the study nurse.

Adverse events were graded according to the National Cancer Institute Common Terminology Criteria for Adverse Events, Version 3.0. Patients removed from study for unacceptable adverse events were followed until resolution or stabilization of the adverse event.

\section{Statistical Methods}

A Simon two-stage phase II design with a null hypothesis of an RR of $10 \%$ and an alternative hypothesis of an RR of

\begin{tabular}{|c|c|}
\hline Characteristic & Value \\
\hline Median age (range), yrs & $56(33-80)$ \\
\hline Gender (female:male) & $20: 0$ \\
\hline ECOG performance status score $(0: 1)$ & $9: 11$ \\
\hline Estrogen receptor positive & $14(70 \%)$ \\
\hline $\begin{array}{l}\text { Human epidermal growth factor receptor } \\
2 / \text { neu amplification/overexpression }\end{array}$ & 0 \\
\hline \multicolumn{2}{|l|}{ Stage at study entry } \\
\hline Metastatic & $17(85 \%)$ \\
\hline Incurable recurrent & $3(16 \%)$ \\
\hline$n$ of prior CT regimens ${ }^{\mathrm{a}}(0: 1: 2)$ & $2: 14: 4$ \\
\hline \multicolumn{2}{|l|}{ Prior therapy } \\
\hline Neoadjuvant CT & $2(11 \%)$ \\
\hline Adjuvant CT & $13(65 \%)$ \\
\hline Palliative CT & $13(65 \%)$ \\
\hline Radiotherapy & $16(80 \%)$ \\
\hline Prior anthracycline & $14(70 \%)$ \\
\hline Prior taxane & $9(45 \%)$ \\
\hline \multicolumn{2}{|c|}{$\begin{array}{l}{ }^{a} \text { CT given in any line (e.g., neoadjuvant, adjuvant, or } \\
\text { palliative). } \\
\text { Abbreviations: CT, chemotherapy; ECOG, Eastern } \\
\text { Cooperative Oncology Group. }\end{array}$} \\
\hline
\end{tabular}

$30 \%$ ( $\alpha$ level, $0.047 ; \beta$ level, 0.098 ) was used [24]. In the first stage, 18 evaluable patients were to be enrolled. If three or more responses were observed, an additional 17 evaluable patients would be enrolled in stage 2 for a total of 35 evaluable patients. The drug would be considered active if seven or more responses were seen in 35 patients $(\geq 20 \%$ ORR). Survival estimates and time-to-event variables were computed using the Kaplan-Meier method. All patients were evaluable for toxicity from the time of their first dose of pazopanib. As an exploratory analysis, RRs and time-toevent variables were compared according to the development of hypertension.

\section{RESUltS}

\section{Patient Demographics and Disease Characteristics}

Twenty-one female patients were enrolled from August 2007 to June 2008. All received at least one dose of pazopanib and were included in the toxicity analysis. One was nonevaluable because she was withdrawn during the first week of treatment after the discovery of brain metastases. Another withdrew early for toxicity, including grade 3 headache, hypertension, and chest pain, and did not have tumor measurements for response, but she was included in 
the response assessment as not evaluable. Because of simultaneous accrual, the target for stage I accrual was exceeded and 20 patients were ultimately evaluated for response.

The baseline demographic and disease characteristics of the evaluable patients are shown in Table 1 . Three patients (15\%) presented with de novo MBC. Thirteen patients $(65 \%)$ had received prior chemotherapy for advanced disease.

\section{Treatment}

The median number of treatment cycles was three (range, $1-20$ ) in the 20 evaluable patients (Table 2). Fifteen (75\%) discontinued treatment because of progressive disease and five $(25 \%)$ discontinued treatment because of adverse events, including: grade 3 headache $(n=1)$, grade 3 transaminitis $(n=1)$, grade 2 dyspepsia and weight loss $(n=1)$, grade 3 headache, hypertension, and chest pain $(n=1)$, and grade 3 gastrointestinal hemorrhage $(n=1)$. Two patients had treatment delays, and 12 had dose reductions (four to $600 \mathrm{mg}$, eight to $400 \mathrm{mg}$ ).

\section{Efficacy}

Two patients had a PR, but only one was confirmed (5\%), which did not meet the predefined criteria to expand to stage 2 of the study. Eleven $(55 \%)$ had SD (four of whom had pSD, $20 \%$ ) and seven (35\%) had progressive disease (PD) as their best response, and one (5\%) was not evaluable. At 6 months, $22 \%$ of patients (95\% confidence interval [CI], 8\%-58\%) were progression free. The median overall survival time was 12.8 months (95\% CI, 7.6 months to not reached) (Table 2). The CBR was $25 \%$ ( $n=5$ patients). The median TTP was 5.3 months (95\% CI, 1.8-9.0) (Fig. 1).

Ten patients $(50 \%)$ had at least some decrease in their target lesions, as seen in Figure 2 (waterfall plot demonstrating the maximal tumor shrinkage). Two patients did not have tumor measurements available - one because of PD based on new lesions and the other withdrew from the study prior to the first response assessment. Six of these 10 patients had one line of prior chemotherapy for advanced disease.

The responding patient had estrogen receptor $(E R)^{+}$ breast cancer with bone and visceral metastases, had prior adjuvant chemotherapy only, and had completed four cycles of treatment with pazopanib before stopping for toxicity (grade 2 heartburn and weight loss). The patient who was on treatment for 20 cycles had $\mathrm{ER}^{+}$locally advanced breast cancer, and had received prior docetaxel only for advanced disease. That patient had ongoing hypertension (maximum, grade 3), requiring two dose reductions to 400 $\mathrm{mg}$, and later her disease progressed.

Of the 12 patients who had SD or a PR, nine (75\%) developed hypertension, whereas three of the seven (43\%) who had

\begin{tabular}{|c|c|}
\hline Measure & Result \\
\hline Median $n$ of cycles/patient (range) & $3(1-20)$ \\
\hline $\begin{array}{l}\text { Median } n \text { of cycles in patients } \\
\text { with SD or PR (range) }\end{array}$ & $6(2-20)$ \\
\hline \multicolumn{2}{|l|}{$\begin{array}{l}\text { Reason for treatment } \\
\text { discontinuation }\end{array}$} \\
\hline PD & $15(75 \%)$ \\
\hline Adverse event & $5(25 \%)$ \\
\hline \multicolumn{2}{|l|}{ Best response } \\
\hline $\mathrm{CR}$ & 0 \\
\hline PR & $1(5 \%)$ \\
\hline SD & $11(55 \%)$ \\
\hline PD & $7(35 \%)$ \\
\hline $\mathrm{NE}$ & $1(5 \%)$ \\
\hline $\begin{array}{l}\text { Median duration of response } \\
\text { and/or SD (range) }\end{array}$ & $\begin{array}{l}5.3 \operatorname{mos}(2-20 \\
\operatorname{mos})\end{array}$ \\
\hline $\begin{array}{l}\text { Progression free at } 6 \text { mos } \\
(95 \% \mathrm{CI})\end{array}$ & $22 \%(8 \%-58 \%)$ \\
\hline $\begin{array}{l}\text { Median time to progression } \\
(95 \% \mathrm{CI})\end{array}$ & $\begin{array}{l}5.3 \mathrm{mos}(1.8- \\
9.0 \mathrm{mos})\end{array}$ \\
\hline $\begin{array}{l}\text { Median overall survival } \\
(95 \% \mathrm{CI})\end{array}$ & $\begin{array}{l}12.8 \text { mos }(7.6 \\
\text { to not reached })\end{array}$ \\
\hline $\begin{array}{l}\text { Clinical benefit rate (CR, PR, or } \\
\mathrm{SD} \geq 6 \text { mos) }\end{array}$ & $5(25 \%)$ \\
\hline
\end{tabular}

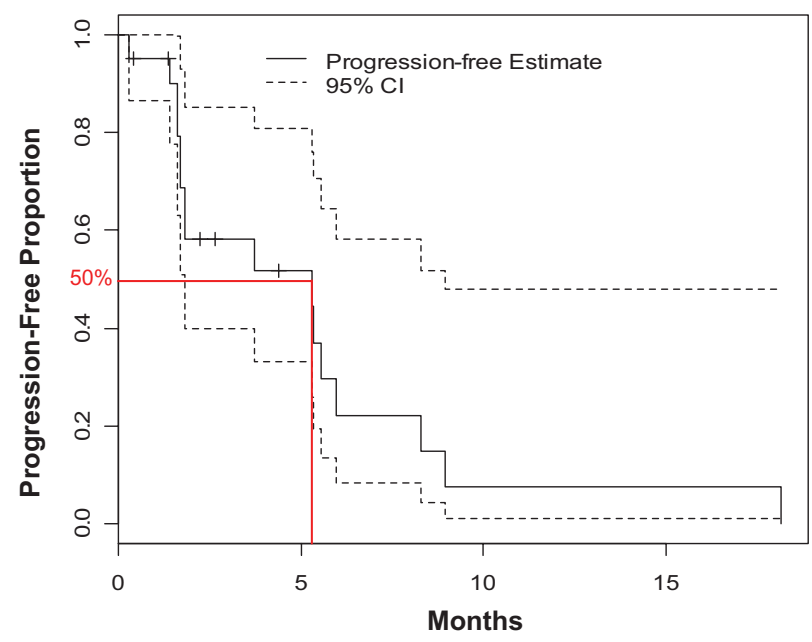

Figure 1. Time to progression of single-agent pazopanib in metastatic or recurrent breast cancer (median, 5.3 months; 95\% confidence interval (CI), 1.8-9.0).

PD developed hypertension ( $p=.33$ ). Development of hypertension was associated with a longer TTP-5.3 months (95\% CI, 3.7 months to not reached), versus 1.7 months (95\% CI, 1.6 months to not reached) in those without hypertension. 

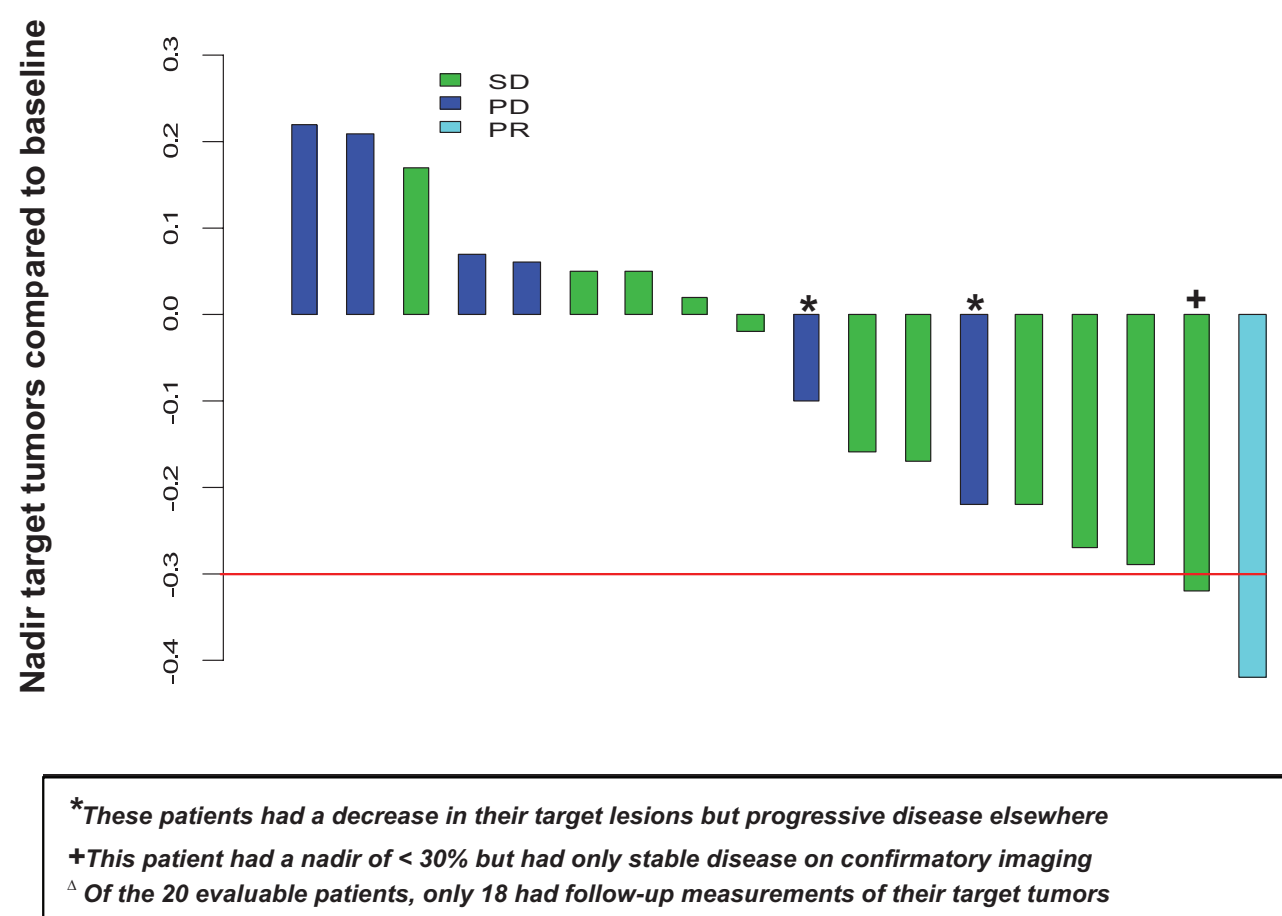

Figure 2. Target lesion response to pazopanib in metastatic or recurrent breast cancer $\left(n=18^{\Delta}\right)$.

Abbreviations: PD, progressive disease; PR, partial response; SD, stable disease.

\section{Safety}

Tables 3 and 4 list the common adverse events deemed at least possibly related to pazopanib and include all 21 patients who received at least one dose of study drug. The most common grade 3 events were elevations in aspartate aminotransferase $(n=3,14 \%)$, hypertension $(n=3,14 \%)$, and neutropenia $(n=3,14 \%)$.

There were no grade 5 adverse events, but there was one grade 4 adverse event. Grade 4 alanine aminotransferase (ALT) elevation was seen in one patient, during cycle 2 of study treatment; treatment was held and the dose was reduced with improvement, and the ALT later normalized when the patient stopped therapy at her request.

In contrast to effects observed in other studies with pazopanib, there were no arterial thromboembolic events observed.

\section{DISCUSSION}

Here, we report the safety and efficacy of single-agent pazopanib in advanced recurrent breast cancer or MBC. Although dose reductions resulting from adverse events were often required, pazopanib did not cause significant severe toxicity, with a low incidence of grade 4 events and no treatment-related deaths. The trial did not meet the predefined response criteria for proceeding to stage 2 , and was therefore terminated. The majority of the toxicities seen are in keeping with those reported with other drugs causing VEGF inhibition (hypertension, gastrointestinal hemorrhage in one patient), KIT inhibition (skin hypopigmentation), and transaminitis and gastrointestinal toxicity, as commonly seen with other small molecule tyrosine kinase inhibitors.

In our study, there was evidence of disease stabilization (rate, 55\%) with pazopanib, with a median TTP of 5.3 months (95\% CI, 1.8-9.0). Half of the patients had a decrease in their target lesion size. A PR or SD occurred in 12 patients $(60 \%)$, with prolonged SD in four patients $(20 \%)$, for a total CBR of $25 \%$. These results suggest that there may be cytostatic activity of pazopanib in advanced breast cancer.

It is of note that the use of RR as a primary endpoint in breast cancer clinical trials of molecularly targeted agents may have limited utility. Tumor shrinkage is often modest and the majority of the activity may be through disease stabilization. Therefore setting ORR as the primary endpoint may result in stopping the development of a potentially clinically important drug. Higher RRs also do not necessarily translate into a survival benefit, the gold standard for endpoints in oncology trials [25]. Conversely, VEGF inhibitors can yield a survival advantage when added to cytotoxic chemotherapy in solid tumors, with only a modest improvement in response, as demonstrated in colorectal 
Table 3. Laboratory adverse events at least possibly related to pazopanib $\left(n=21^{\mathrm{a}}\right)$

\begin{tabular}{|c|c|c|c|}
\hline Toxicity & $\begin{array}{l}n \text { of } \\
\text { patients, } \\
\text { any } \\
\text { grade }\end{array}$ & $\begin{array}{l}n \text { of } \\
\text { patients, } \\
\text { grade } 1 \\
\text { or } 2 \\
\end{array}$ & $\begin{array}{l}n \text { of } \\
\text { patients, } \\
\text { grade } 3 \\
\text { or } 4^{b}\end{array}$ \\
\hline Leukopenia & $14(67 \%)$ & $12(57 \%)$ & $2(10 \%)$ \\
\hline Lymphopenia & $13(62 \%)$ & $11(52 \%)$ & $2(10 \%)$ \\
\hline $\begin{array}{l}\text { Alanine } \\
\text { aminotransferase }\end{array}$ & $11(52 \%)$ & $9(43 \%)$ & $2(10 \%)$ \\
\hline Neutropenia & $10(48 \%)$ & $7(33 \%)$ & $3(14 \%)$ \\
\hline $\begin{array}{l}\text { Aspartate } \\
\text { aminotransferase }\end{array}$ & $10(48 \%)$ & $7(33 \%)$ & $3(14 \%)$ \\
\hline Alkaline phosphatase & $5(24 \%)$ & $5(24 \%)$ & 0 \\
\hline Bilirubinemia & $5(24 \%)$ & $5(24 \%)$ & 0 \\
\hline Hypoglycemia & $5(24 \%)$ & $4(19 \%)$ & $1(5 \%)$ \\
\hline Anemia & $4(19 \%)$ & $4(19 \%)$ & 0 \\
\hline Hypokalemia & $4(19 \%)$ & $3(14 \%)$ & $1(5 \%)$ \\
\hline Thrombocytopenia & $3(14 \%)$ & $3(14 \%)$ & 0 \\
\hline Hyperglycemia & $2(10 \%)$ & $1(5 \%)$ & $1(5 \%)$ \\
\hline Hypophosphatemia & $2(10 \%)$ & $1(5 \%)$ & $1(5 \%)$ \\
\hline
\end{tabular}

cancer patients [26]. Therefore, the use of time-to-event endpoints such as TTP or PFS may be more appropriate in clinical trials of angiogenesis inhibitors [27].

Pazopanib appears to have single-agent activity, including the CBR and TTP, similar to that of other targeted inhibitors of angiogenesis in advanced pretreated breast cancer, such as sunitinib (6-month CBR, 16\%; median TTP, 2.3 months) [28], bevacizumab (5-month CBR, 17\%; median TTP, 2.4 months) [29], and sorafenib (6-month CBR, 10\%-13\%; median TTP, 1.9 months) [30, 31]. The PFS rate was also similar in our study, with $22 \%$ of patients progression free at 6 months (sunitinib, 15\%; bevacizumab at 5 months, $16 \%$; sorafenib, $10 \%$ ). There were obvious differences in the patient populations and definitions of endpoints among these studies. Our study of single-agent pazopanib was powered to detect an RR of $\geq 20 \%$, a larger difference than in the other trials. Despite these factors, pazopanib had a higher CBR $(25 \%)$. However, one must interpret intertrial comparisons with great caution given differences in design, patient characteristics, and sample size.

Although pazopanib did not demonstrate efficacy in inducing response as a single agent, it may be useful in studies of combination therapy, although the dose may need to be reduced when used in combination to improve tolerability. Bevacizumab has demonstrated superior RRs and PFS rates
Table 4. Clinical adverse events at least possibly related to pazopanib $\left(n=21^{\mathrm{a}}\right)$

\begin{tabular}{|c|c|c|c|}
\hline Toxicity & $\begin{array}{l}n \text { of } \\
\text { patients, } \\
\text { any } \\
\text { grade }\end{array}$ & $\begin{array}{l}n \text { of } \\
\text { patients, } \\
\text { grade } 1 \\
\text { or } 2\end{array}$ & $\begin{array}{l}n \text { of } \\
\text { patients, } \\
\text { grade } 3^{\text {b }}\end{array}$ \\
\hline Diarrhea & $13(62 \%)$ & $12(57 \%)$ & $1(5 \%)$ \\
\hline Fatigue & $12(57 \%)$ & $11(52 \%)$ & $1(5 \%)$ \\
\hline $\begin{array}{l}\text { Skin/hair } \\
\text { hypopigmentation }\end{array}$ & $12(57 \%)$ & $12(57 \%)$ & 0 \\
\hline Hypertension & $11(52 \%)$ & $8(38 \%)$ & $3(14 \%)$ \\
\hline Nausea & $10(48 \%)$ & $10(48 \%)$ & 0 \\
\hline Headache & $9(43 \%)$ & $8(38 \%)$ & $1(5 \%)$ \\
\hline Anorexia & $8(38 \%)$ & $8(38 \%)$ & 0 \\
\hline Vomiting & $7(33 \%)$ & $7(33 \%)$ & 0 \\
\hline Proteinuria & $7(33 \%)$ & $7(33 \%)$ & 0 \\
\hline Blurred vision & $3(14 \%)$ & $2(10 \%)$ & $1(5 \%)$ \\
\hline $\begin{array}{l}\text { Gastrointestinal } \\
\text { hemorrhage }\end{array}$ & $1(5 \%)$ & 0 & $1(5 \%)$ \\
\hline Esophagitis & $1(5 \%)$ & 0 & $1(5 \%)$ \\
\hline Fever & $1(5 \%)$ & 0 & $1(5 \%)$ \\
\hline Glaucoma & $1(5 \%)$ & 0 & $1(5 \%)$ \\
\hline Pneumonitis & $1(5 \%)$ & 0 & $1(5 \%)$ \\
\hline
\end{tabular}

in phase III trials when combined with taxanes, anthracyclines, or capecitabine as first-line therapy in MBC patients [32-34]. A phase III study of the addition of bevacizumab to capecitabine in MBC patients also demonstrated a significantly higher RR [35].

The future of therapy in breast cancer may include combinations of targeted agents based on multiple biological pathway activation, redundancy in pathways, and crosstalk between pathways. Pazopanib and lapatinib (an oral inhibitor of epidermal growth factor receptor and HER-2) have been combined for dual signaling pathway blockade in HER $-2^{+}$advanced breast cancer or MBC patients [36, 37]. In a randomized phase II study, patients received daily treatment with pazopanib, at $400 \mathrm{mg}$, plus lapatinib $(1,000$ $\mathrm{mg})(n=69)$ or lapatinib $(1,500 \mathrm{mg})$ alone $(n=72)$. The primary endpoint, the 12 -week PD rate, was $36.2 \%$ in the combination arm versus $38.9 \%(p=.37)$ in the lapatinib arm. The estimated PFS rate at 12 weeks was $84.1 \%$ in the combination arm versus $63.2 \%$ in the lapatinib arm (hazard ratio, $0.41 ; p=.0091)$. The ORR at week 12 was $44.9 \%$ versus $27.8 \%$ ( $p$-value not reported), in favor of the combination. Almost all patients in the combination arm had a decrease in their target lesions [36]. These results suggest that 
pazopanib has activity when administered with HER-2directed therapy as combined targeted therapy, but this strategy may be limited by toxicity.

Given that traditional endpoints such as RR may not be useful with agents such as pazopanib, biomarkers for response to VEGF-directed therapy are needed to identify patients most likely to benefit from such treatment. Currently, there are no such validated predictive clinical biomarkers $[38,39]$.

Clinical trials in various solid tumors have shown that a higher RR or PFS rate when treating with angiogenesis inhibitors (including pazopanib) is associated with various markers, such as plasma VEGF levels and other angiogenic factors, circulating endothelial cells, and monocytes [40-43]. Correlative studies of biomarkers were not performed in the current trial. Recent studies have also examined class side effects of anti-VEGF therapy as possible predictive markers. When patients with various solid tumors were treated with axitinib, development of diastolic hypertension was associated with a significantly higher RR and lower risk for death [44]. Comparable findings were seen with cediranib in advanced non-small cell lung cancer, whereby patients who developed hypertension had a significantly higher RR and PFS rate [45]. In a phase III study of paclitaxel with or without bevacizumab in advanced breast cancer, patients in the bevacizumab arm who developed hypertension survived longer than those who did not [46].

In our study of pazopanib, nine of the 12 patients (75\%) who had SD or a PR developed hypertension, whereas only three of the seven $(43 \%)$ who had PD developed hypertension $(p=.33)$. Similarly, the TTP was longer in patients who developed hypertension-5.3 months (95\% CI, 3.7 months to not reached), versus 1.7 months (95\% CI, 1.6 months to not reached) in those who did not. These observations are exploratory and are not powered to draw any significant conclusions. Hypertension as a predictive marker of response to antiangiogenic therapy needs to be further validated in prospective phase III studies. Furthermore, an understanding is required of the mechanism by which hypertension impacts response to antiangiogenic therapy, whether it be by pharmacokinetics, pharmacodynamics, pharmacogenomics, duration of therapy, or any combination of these possible factors.

In conclusion, this multicentre phase II study of singleagent pazopanib in advanced breast cancer or MBC patients did not meet the predefined criteria for efficacy and therefore the trial was closed to accrual after stage I. However, based on the suggestion of cytostatic activity demonstrated in this trial, the clinical benefit of pazopanib in breast cancer should be explored further in combination with systemic therapy and/or other targeted agents. Clinical trials of similar targeted agents in breast cancer should consider using more relevant endpoints that take into account the mechanism of action of the agent and intrinsic biology of the breast cancer. Doing so may prevent the early dismissal of a compound that has some potential benefit in the treatment of MBC.

\section{ACKNOWLEDGMENTS}

We gratefully acknowledge the contributions of L. Wong, H. Kennecke, C. Lohrish, K. Gelmon, T. Shenkier, British Columbia Cancer Agency; D. Keller, D. Robbins, S. Verma, X. Song, Ottawa Hospital Cancer Centre; and L. Adams, I. Tannock, L. Bordelau, L. Siu, Princess Margaret Hospital.

This work was supported by NCI contract number N01CM-62203.

This work was presented in part at the 2009 ASCO Annual Meeting, Orlando, Florida, May 31 to June 3, 2009.

\section{Author Contributions}

Conception/Design: Mark Agulnik, Percy Ivy, Amit M. Oza, Kathleen I. Pritchard, Natasha B. Leighl

Administrative support: Amit M. Oza

Provision of study material or patients: Mark Clemons, Stephen Chia, Susan Dent, Natasha B. Leighl

Collection and/or assembly of data: Mark Clemons, Amit M. Oza, Pamela Grenci, Stephen Chia, Susan Dent, Natasha B. Leighl

Data analysis and interpretation: Sara K. Taylor, Mark Clemons, Lisa Wang, Percy Ivy, Amit M. Oza, Stephen Chia, Susan Dent, Kathleen I. Pritchard, Natasha B. Leighl

Manuscript writing: Sara K. Taylor, Mark Clemons, Stephen Chia, Susan Dent, Kathleen I. Pritchard, Natasha B. Leighl

Final approval of manuscript: Sara K. Taylor, Mark Clemons, Mark Agulnik, Lisa Wang, Percy Ivy, Amit M. Oza, Stephen Chia, Susan Dent, Kathleen I. Pritchard, Natasha B. Leighl

\section{REFERENCES}

1 Jemal A, Siegel R, Ward E et al. Cancer Statistics, 2009. CA Cancer J Clin 2009:59:225-249.

2 Hortobagyi GN. Treatment of breast cancer. N Engl J Med 1998;339:974984.

3 Chia SK, Speers CH, D'Yachkova Y et al. The impact of new chemotherapeutic and hormone agents on survival in a population-based cohort of women with metastatic breast cancer. Cancer 2007;110:973-979.
4 Ferrara N, Kerbel RS. Angiogenesis as a therapeutic target. Nature 2005; 438:967-974.

5 Nakopoulou L, Stefanaki K, Panayotopoulou E et al. Expression of the vascular endothelial growth factor receptor-2/Flk-1 in breast carcinomas: Correlation with proliferation. Hum Pathol 2002;33:863-870.

6 Ostman A. PDGF receptors-mediators of autocrine tumor growth and regulators of tumor vasculature and stroma. Cytokine Growth Factor Rev 2004; 15:275-286. 
7 Betsholtz C. Insight into the physiological functions of PDGF through genetic studies in mice. Cytokine Growth Factor Rev 2004;15:215-228.

8 Relf M, LeJeune S, Scott PA et al. Expression of the angiogenic factors vascular endothelial cell growth factor, acidic and basic fibroblast growth factor, tumor growth factor beta-1, platelet-derived endothelial cell growth factor, placenta growth factor, and pleiotrophin in human primary breast cancer and its relation to angiogenesis. Cancer Res 1997;57:963-969.

9 Yoshiji H, Gomez DE, Shibuya M et al. Expression of vascular endothelial growth factor, its receptor, and other angiogenic factors in human breast cancer. Cancer Res 1996;56:2013-2016.

10 Carvalho S, e Silva AO, Milanezi F et al. c-KIT and PDGFRA in breast phyllodes tumours: Overexpression without mutations? J Clin Pathol 2004; 57:1075-1079.

11 Manders P, Beex LV, Tjan-Heijnen VC et al. The prognostic value of vascular endothelial growth factor in 574 node-negative breast cancer patients who did not receive adjuvant systemic therapy. Br J Cancer 2002;87:772778 .

12 Paulsson J, Sjoblom T, Micke P et al. Prognostic significance of stromal platelet-derived growth factor $\beta$-receptor expression in human breast cancer. Am J Pathol 2009;175:334-341.

13 Seymour L, Dajee D, Bezwoda WR. Tissue platelet derived-growth factor (PDGF) predicts for shortened survival and treatment failure in advanced breast cancer. Breast Cancer Res Treat 1993;26:247-252.

14 Ariad S, Seymour L, Bezwoda WR. Platelet-derived growth factor (PDGF) in plasma of breast cancer patients: Correlation with stage and rate of progression. Breast Cancer Res Treat 1991;20:11-17.

15 Foekens JA, Peters HA, Grebenchtchikov N et al. High tumor levels of vascular endothelial growth factor predict poor response to systemic therapy in advanced breast cancer. Cancer Res 2001;61:5407-5414.

16 Rhee J, Hoff PM. Angiogenesis inhibitors in the treatment of cancer. Expert Opin Pharmacother 2005;6:1701-1711.

17 Erber R, Thurnher A, Katsen AD et al. Combined inhibition of VEGF and PDGF signaling enforces tumor vessel regression by interfering with pericyte-mediated endothelial cell survival mechanisms. FASEB J 2004;18: 338-340.

18 Da MX, Wu Z, Tian HW. Tumor Lymphangiogenesis and lymphangiogenic growth factors. Arch Med Res 2008;39:365-372.

19 Bergers G, Song S, Meyer-Morse N et al. Benefits of targeting both pericytes and endothelial cells in the tumor vasculature with kinase inhibitors. J Clin Invest 2003;111:1287-1295.

20 Sonpavde G, Hutson TE. Pazopanib: A novel multitargeted tyrosine kinase inhibitor. Curr Oncol Rep 2007;9:115-119.

21 Hurwitz HI, Dowlati A, Saini S et al. Phase I trial of pazopanib in patients with advanced cancer. Clin Cancer Res 2009;15:4220-4227.

22 Sternberg CN, Davis ID, Mardiak J et al. Pazopanib in locally advanced or metastatic renal cell carcinoma: Results of a randomized phase III trial. J Clin Oncol 2010;28:1061-1068.

23 Therasse P, Arbuck SG, Eisenhauer EA et al. New guidelines to evaluate the response to treatment in solid tumors. European Organization for Research and Treatment of Cancer, National Cancer Institute of the United States, National Cancer Institute of Canada. J Natl Cancer Inst 2000;92: 205-216.

24 Simon R. Optimal two-stage designs for phase II clinical trials. Control Clin Trials 1989;10:1-10.

25 Dhani N, Tu D, Sargent DJ et al. Alternate endpoints for screening phase II studies. Clin Cancer Res 2009;15:1873-1882.

26 Grothey A, Hedrick EE, Mass RD et al. Response-independent survival benefit in metastatic colorectal cancer: A comparative analysis of N9741 and AVF2107. J Clin Oncol 2008;26:183-189.

27 Adjei AA, Christian M, Ivy P. Novel designs and end points for phase II clinical trials. Clin Cancer Res 2009;15:1866-1872.

28 Burstein HJ, Elias AD, Rugo HS et al. Phase II study of sunitinib malate, an oral multitargeted tyrosine kinase inhibitor, in patients with metastatic breast cancer previously treated with an anthracycline and a taxane. J Clin Oncol 2008;26:1810-1816.

29 Cobleigh MA, Langmuir VK, Sledge GW et al. A phase I/II dose-escalation trial of bevacizumab in previously treated metastatic breast cancer. Semin Oncol 2003;30(suppl 16):117-124.

30 Moreno-Aspitia A, Morton RF, Hillman DW et al. Phase II trial of sorafenib in patients with metastatic breast cancer previously exposed to anthracyclines or taxanes: North Central Cancer Treatment Group and Mayo Clinic Trial N0336. J Clin Oncol 2009;27:11-15.

31 Bianchi G, Loibl S, Zamagni C et al. Phase II multicenter, uncontrolled trial of sorafenib in patients with metastatic breast cancer. Anticancer Drugs 2009;20:616-624.

32 Miller K, Wang M, Gralow J et al. Paclitaxel plus bevacizumab versus paclitaxel alone for metastatic breast cancer. N Engl J Med 2007;357:26662676.

33 Miles D, Chan A, Romieu G et al. Randomized, double-blind, placebocontrolled, phase III study of bevacizumab with docetaxel or docetaxel with placebo as first-line therapy for patients with locally recurrent or metastatic breast cancer (mBC): AVADO [abstract]. J Clin Oncol 2008; 26:LBA1011.

34 Robert NJ, Dieras V, Glaspy J et al. RIBBON-1: Randomized, doubleblind, placebo-controlled, phase III trial of chemotherapy with or without bevacizumab (B) for first-line treatment of HER2-negative locally recurrent or metastatic breast cancer (MBC) [abstract]. J Clin Oncol 2009;27: 1005 .

35 Miller KD, Chap LI, Holmes FA et al. Randomized phase III trial of capecitabine compared with bevacizumab plus capecitabine in patients with previously treated metastatic breast cancer. J Clin Oncol 2005;23: 792-799.

36 Slamon D, Gomez HL, Kabbinavar FF et al. Randomized study of pazopanib + lapatinib vs. lapatinib alone in patients with HER2-positive advanced or metastatic breast cancer [abstract]. J Clin Oncol 2008;26:1016.

37 Slamon DJ, Stemmer SM, Johnston S et al. Phase 2 study of dual VEGF/ HER2 blockade with pazopanib + lapatinib in patients with first-line HER2 positive advanced or metastatic (adv/met) breast cancer [abstract]. Cancer Res 2009;69:4114

38 Park JW, Kerbel RS, Kelloff GJ et al. Rationale for biomarkers and surrogate end points in mechanism-driven oncology drug development. Clin Cancer Res 2004;10:3885-3896.

39 Jain RK, Duda DG, Clark JW et al. Lessons from phase III clinical trials on anti-VEGF therapy for cancer. Nat Clin Pract Oncol 2006;3:24-40.

40 Hanrahan EO, Ryan AJ, Mann $\mathrm{H}$ et al. Baseline vascular endothelial growth factor concentration as a potential predictive marker of benefit from vandetanib in non-small cell lung cancer. Clin Cancer Res 2009;15:36003609.

41 Hanrahan EO, Lin HY, Kim ES et al. Distinct patterns of cytokine and angiogenic factor modulation and markers of benefit for vandetanib and/or chemotherapy in patients with non-small-cell lung cancer. J Clin Oncol 2010;28:193-201.

42 Nikolinakos P, Altorki N, Guarino M et al. Analyses of plasma cytokine/ angiogenic factors $(\mathrm{C} / \mathrm{AFs})$ profile during preoperative treatment with pa- 
zopanib (GW786034) in early-stage non-small cell lung cancer [abstract]. J Clin Oncol 2008;26:7568.

43 Norden-Zfoni A, Desai J, Manola J et al. Blood-based biomarkers of SU11248 activity and clinical outcome in patients with metastatic imatinibresistant gastrointestinal stromal tumor. Clin Cancer Res 2007;13:26432650.

44 Rini BI, Schiller JH, Fruehauf JP et al. Association of diastolic blood pressure $(\mathrm{dBP}) \geq 90 \mathrm{mmHg}$ with overall survival (OS) in patients treated with axitinib (AG- 013736) [abstract]. J Clin Oncol 2008;26: 3543.
45 Goodwin RAD, Seymour L, Ding K et al. Hypertension (HTN) in National Cancer Institute of Canada Clinical Trials Group study BR. 24: A randomized, double-blind phase II trial of carboplatin (C) and paclitaxel (P) with either daily oral cediranib (CED), an inhibitor of vascular endothelial growth factor receptors, or placebo, in patients with advanced non-small cell lung cancer [abstract]. J Clin Oncol 2009;27:3527.

46 Schneider BP, Wang M, Radovich M et al. Association of vascular endothelial growth factor and vascular endothelial growth factor receptor-2 genetic polymorphisms with outcome in a trial of paclitaxel compared with paclitaxel plus bevacizumab in advanced breast cancer: ECOG 2100. J Clin Oncol 2008;26:4672-4678. 